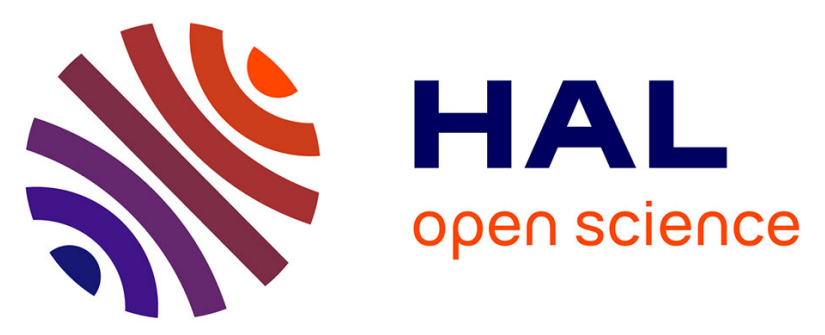

\title{
Multi-channel fibre optic dosimeter based on optically stimulated luminescence for dose verification during radiotherapy treatments
}

Sylvain Magne, Laureline Auger, Aurélie Isambert, André Bridier, Pierre Ferdinand, Jean Barthe

\section{To cite this version:}

Sylvain Magne, Laureline Auger, Aurélie Isambert, André Bridier, Pierre Ferdinand, et al.. Multichannel fibre optic dosimeter based on optically stimulated luminescence for dose verification during radiotherapy treatments. Third European Workshop on Optical Fibre Sensors, SPIE, Jul 2007, naples, Italy. pp.66191N, 10.1117/12.738604 . cea-01840713

\section{HAL Id: cea-01840713 https://hal-cea.archives-ouvertes.fr/cea-01840713}

Submitted on 16 Jul 2018

HAL is a multi-disciplinary open access archive for the deposit and dissemination of scientific research documents, whether they are published or not. The documents may come from teaching and research institutions in France or abroad, or from public or private research centers.
L'archive ouverte pluridisciplinaire HAL, est destinée au dépôt et à la diffusion de documents scientifiques de niveau recherche, publiés ou non, émanant des établissements d'enseignement et de recherche français ou étrangers, des laboratoires publics ou privés. 


\title{
Multi-channel fibre optic dosimeter based on Optically Stimulated Luminescence for dose verification during radiotherapy treatments
}

\author{
Sylvain Magne* ${ }^{\mathrm{a}}$, Laureline Auger ${ }^{\mathrm{a}}$, Aurélie Isambert ${ }^{\mathrm{b}}$, André Bridier ${ }^{\mathrm{b}}$, Pierre Ferdinand ${ }^{\mathrm{a}} \&$ Jean Barthe $^{\mathrm{a}}$ \\ ${ }^{a}$ CEA LIST - Laboratoire de Mesures Optiques, Centre d'Etudes de Saclay, Bât. 528, Point courrier 94 \\ 91191 Gif-sur-Yvette FRANCE \\ ${ }^{\mathrm{b}}$ Institut Gustave Roussy (IGR) - Service de Physique, 39 rue Camille Desmoulins \\ 94805 Villejuif FRANCE
}

\begin{abstract}
A multi-channel fibre optic OSL dosimeter system is developed by the CEA LIST for quality control in cancer radiation therapy, in the framework of the European Integrated Project MAESTRO.
\end{abstract}

Keywords: Optical Fibre Sensor (OFS), Optically Stimulated Luminescence (OSL), Radioluminescence (RL), Dosimetry, Radiation Therapy.

\section{INTRODUCTION}

At the beginning of the third millennium, one European citizen out of three will have to deal with a cancer episode in the course of his/her life. Worldwide, the estimated number of new cancer cases each year is expected to rise from 10 millions in 2000 to 15 millions by 2020 . Within the European Union, it is over 1.5 million new cancer cases that are diagnosed every year. Therefore, combating cancer is a major societal and economical issue for developed countries.

About $60 \%$ of all cancer patients are now treated by Radiation Therapy (RT) thanks to the technical progress in irradiation equipment in the last ten years. For external radiotherapy for instance, high energy photon or electron beams are mainly produced by linear accelerators, while some limited number of proton synchrotrons are used for the treatment of cancers close to vulnerable organs (eyes, optical and auditory nerves, spinal cords).

The so-called conformal RT and Intensity-Modulated RT (IMRT) improve the conformity of the dose distribution to the target leading to a reduced dose to surrounding healthy tissues and critical organs.

A multi-sensor in-vivo dosimetry (both external and internal) is needed to check the accordance between planned and delivered doses (the difference should remain below pre-determined thresholds, typically 5\%). Increased legal requirements in quality control are foreseen in a near future for patient dosimetry.

Considering the specificities of these techniques (high dose gradients), there is thus a need to provide an efficient and reliable dosimeter system in the purpose of fulfilling the quality control for in-vivo dosimetry.

However, these innovative RT techniques bring additional costs due to time-consuming preparations of treatment plannings (of increasing complexity) as well as sensor replacement and calibration tasks. Therefore, the ideal dosimeter system should be also easy to use and cost-effective, respectively in the purpose of saving time and maintenance cost (sensor replacement / calibration, system exploitation, data analysis and storage), as well as safe and reliable, all key issues for gaining wide acceptance from medical physicists.

OSL sensors and systems are potentially very attractive for RT applications ${ }^{1-3}$.

In such context, an Integrated Project (IP) of the $6^{\text {th }}$ Framework Program of the European Community has been launched in 2004. The MAESTRO Project (Methods and Advanced Equipments for the Simulation and Treatment in Radio Oncology), led by the CEA LIST, is dedicated to the development of several technologies and treatment techniques in cancer Radiation Therapy.

This paper reports on our investigations aimed towards applying OSL dosimetry to dose verification in Radiation Therapy involving photon beams. The CEA LIST (Saclay, France) collaborates with the Institut Gustave Roussy (Villejuif, France), first cancer treatment center in Europe.

*sylvain.magne@cea.fr; phone 331690890 47; fax 33169088395

Third European Workshop on Optical Fibre Sensors, Antonello Cutolo, Brian Culshaw, José Miguel López-Higuera, Eds., Proceedings of SPIE Vol. 6619,66191N, (2007) $\cdot 0277-786$ X/07/\$18 $\cdot$ doi: 10.1117/12.738604 


\section{OSL DOSIMETER SYSTEM}

\subsection{Principle of Optically Stimulated Luminescence (OSL)}

Optically Stimulated Luminescence (OSL) dosimetry is similar to the well-known ThermoLuminescence Dosimetry (TLD) except that the luminescence is stimulated by light instead of heat, opening the way to a remote and operational optical interrogation.

During irradiation, a fraction of the electrons are promptly recombined and generate a RadioLuminescence (RL). Others are trapped at defect sites in the crystal lattice and remain stored for undetermined periods of time. The stimulation spectrum is related to the trap center and the OSL spectrum is related to the recombination center. Since the stimulating wavelength is longer than the OSL wavelength, the OSL does not overlap with usual Stokes fluorescence.

Electrons are released on request by a laser light and produce an OSL that decays as the trap levels are emptied. The integral (over time) of the OSL signal is proportional to the dose absorbed by the OSL material between two successive stimulations. The time decay of the OSL is inversely proportional to light intensity $\left(\mathrm{W} \cdot \mathrm{m}^{-2}\right.$ ) and also depends on laser wavelength with respect to the stimulation spectrum.

$\mathrm{Al}_{2} \mathrm{O}_{3}$ crystals are very interesting OSL transducers for personal dosimetry because they are very sensitive, they show little if not loss of information (fading) at room temperature ${ }^{4}$ and can be used both as integrators (OSL) or scintillators $(\mathrm{RL})$. They are optically transparent and non-hygroscopic and the effective atomic number of $\mathrm{Al}_{2} \mathrm{O}_{3}$ is low $(\mathrm{Z} \sim 10)$.

\subsection{Description of the OSL system}

During the past 12 years, the CEA LIST has developed several OSL prototypes for performing remote dose measurements either for the dismantling of French nuclear installations ${ }^{5}$ or for Radiation Protection ${ }^{6}$. Based on alumina crystals (provided by Landauer Inc.), a dose resolution of $20 \mu \mathrm{Gy}$ has been demonstrated in a previous project with a prototype equipped with a 20 -meter long fibre ${ }^{6}$.

The OSL dosimeter developed within the MAESTRO Project works in a "conventional" OSL mode, simple and convenient for achieving delayed OSL measurements (i.e. sequentially read after treatment). Every OSL sensor is remotely stimulated via an optical fibre using a Diode-Pumped Solid-State (DPSS) laser (@ $532 \mathrm{~nm}, 200 \mathrm{~mW}$ ). The OSL (@ $410 \mathrm{~nm}$ ) is collected and guided back along the same fibre to a photomultiplier tube through appropriate optical filters. OSL signals are corrected for background noise and integrated to provide the absorbed doses. The light stimulation also fully bleaches the crystals so that they can be remotely read in operation (reusable for the next patient). Moreover, this system incorporates a 16-channel fibre switch that provides a cost-effective sensor interrogation.

The OSL system will be located in a control room (next to the irradiation room), handled by a laptop through a dedicated software written in Lab-View ${ }^{\circledR}$.

Precautionary measures must be taken in the perspective of a medical use of the OSL system.

Firstly, a self-test function checks every critical device to make sure that the instrumentation is operational before treatment. Secondly, since the dose value is proportional to the OSL signal, any abnormal change in fibre transmission (for instance, due to a misconnection) will lead to an underestimation of the dose. This is, of course, unacceptable in a medical context. Therefore, fibre transmissions (ratios return power / laser power) are monitored in real-time with two photodiodes incorporated in the system and an alarm is triggered whenever they exceed a pre-determined threshold. Finally, eye safety linked to the use of a class IIIb laser is also taken into account. Any drop in transmission (due to disconnection or fibre breakage) is detected early in order to shut down the laser beam and avoid a hypothetical accident.

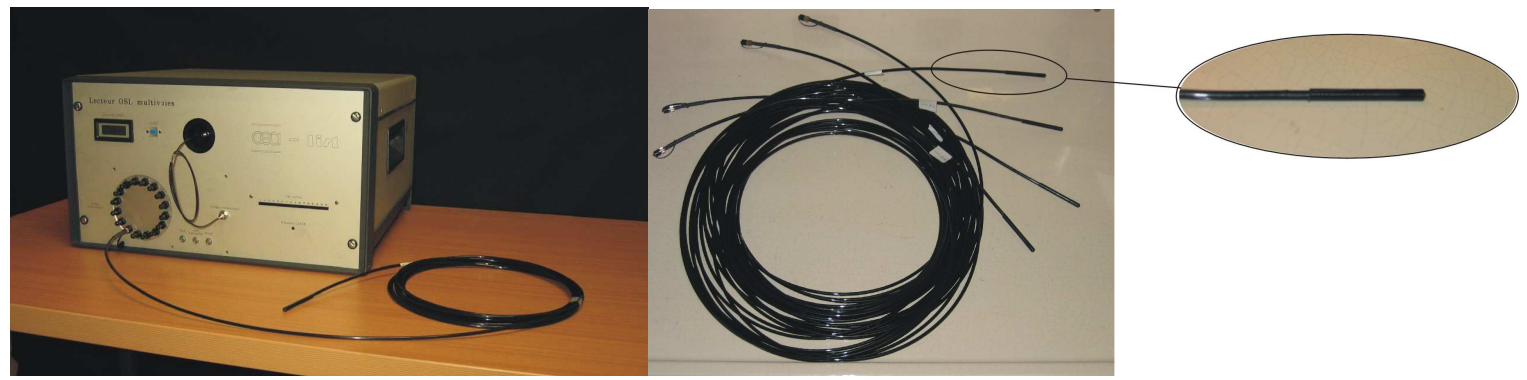

Fig. 1.: View of the OSL dosimeter of the CEA LIST and fibre sensors 


\subsection{Description of OSL sensors}

The sensors are compatible with in-vivo applications (small size $(\mathrm{mm})$ and sterilizable), are immune to electromagnetic perturbations and exhibit low energy and angular dependences ${ }^{1}$, partly due to cylindrical symmetry and homogeneity of the crystal dimensions. Based on silica fiber, the fibre sensor is nearly radiation-transparent. As a solid-state sensor, its stability and lifetime is potentially important.

Each fibre sensor consists of an optical cable with a SMA connector at one end and a molded cylindrical head at the other (fig. 1). The radiation-transparent head (made with polymers) protects the OSL crystal ( $\varnothing=1 \mathrm{~mm}, 1 \mathrm{~mm}$ long) affixed near the end of a silica fibre $(\varnothing=600 \mu \mathrm{m}$, N.A. $=0.37)$.

\section{PLANNED USE OF THE DEVICE IN CLINICS}

The OSL system is suitable to usual Radiation Therapy and IMRT for which the dose is delivered at a very localized part of the human body (i.e. at the tumor). For all these treatments, the absorbed dose is measured after irradiation during the inter-patient time.

Some patients may also receive radiation of their entire body, also called Total Body Irradiation (TBI) in preparation for a spinal cord cell transplant. TBI treatments require a real-time estimation of the cumulated dose (to provide feedback to the physician during treatment). This is obtained by integrating the RL signals emitted by the sensors. In this operating mode, the RL signals are time-sampled by the optical switch and a routine calculates the cumulated dose for each sensor. After the TBI treatment, the crystal is bleached for a next usage and the OSL is also measured to get the absorbed dose. The OSL enables a more accurate estimation of the absorbed dose rather than by numerical integrating the RL signal. The reason for that is twofold: firstly, OSL sensors are true integrating dosimeters and secondly, the RL sensitivity increases slightly with the dose (as can be seen on fig. 2) and thus requires a dedicated calibration ${ }^{1,7}$.

The RL signal is mainly due to scintillation of the alumina crystal (located at the sensor head) but potentially affected by fluorescence and Cerenkov light generated in the optical fibre (distributed along its length). Practically, this so-called "stem effect" is small with respect to the useful signal $\left(6 \%\right.$ at $6 \mathrm{MV}$ and $2.5 \%$ at $\left.18 \mathrm{MV}^{4}\right)$. We have tested several orientations of a one-meter long fibre with respect to our accelerator beam (Saturn 43) and we concluded that the relative amount of distributed light is about $5 \%$ to $10 \%$ of the RL light.

Two methods may be applied to compensate for this stem effect.

The first one consists in removing the Cerenkov part from the RL signal using a gating technique. This is feasible with $\alpha-\mathrm{Al}_{2} \mathrm{O}_{3}$ crystals because the time constant of the scintillation light is $35 \mathrm{~ms}$ so that the Cerenkov contribution may be discriminated in time against the scintillation light ${ }^{7}$. This method is suitable to pulsed linear accelerator beams but requires a gating signal from the accelerator, which is not always available in practice.

The second method consists in placing a blank optical fibre (i.e. without crystal attached) in parallel with and aside the fibre sensor. The luminescence from the reference fibre is then subtracted from that measured with the fibre sensor. We have chosen this solution because it may be easily implemented in a medical context with our multi-channel system.

\section{PRELIMINARY TESTS}

Preliminary tests have been performed using an X-ray generator $(80 \mathrm{keV}, 0.15 \mathrm{~Gy} / \mathrm{min})$ and a Saturn 43 linear accelerator (photons beams of $6 \mathrm{MV}, 12 \mathrm{MV}, 20 \mathrm{MV}$ ) located in the Laboratoire National Henri Becquerel (LNHB, CEA-Saclay). As an example, let us consider a continuous exposition during 2 minutes by the generator (fig. 2). The RL (observed during the irradiation exposure) provides an estimation of the dose rate ( $\left.4.810^{4} \mathrm{cts} / \mathrm{mGy}\right)$. Then, the laser shutter is opened to stimulate the OSL and the OSL signal (with a decaying shape) is recorded and integrated $\left(\sim 1.210^{4}\right.$ cts/mGy). The crystal is bleached within 24 seconds ( $99.9 \%$ of bleaching of trap levels) for $15 \mathrm{~mW}$ at the fibre end. An additional time of about $6 \mathrm{~s}$ is needed to record the background noise that is subtracted to provide the dose measurement.

\section{CONCLUSION}

Our preliminary tests confirm the great potential of the OSL dosimetry technique for RT applications. Our system provides both a real-time estimation of the cumulated dose (RL) and accurate measurements of the absorbed doses (delayed OSL). The dose resolution of our system is $\sim 1 \mathrm{mGy}$ and response time is less than half a minute. 
Pre-clinical validation tests are planned on a Saturn 43 linear accelerator to check the energy response, angular response and dose reproducibility. Clinical validations will then be carried out at IGR facilities to validate the instrumentation in real clinical conditions on body simulators (phantoms).

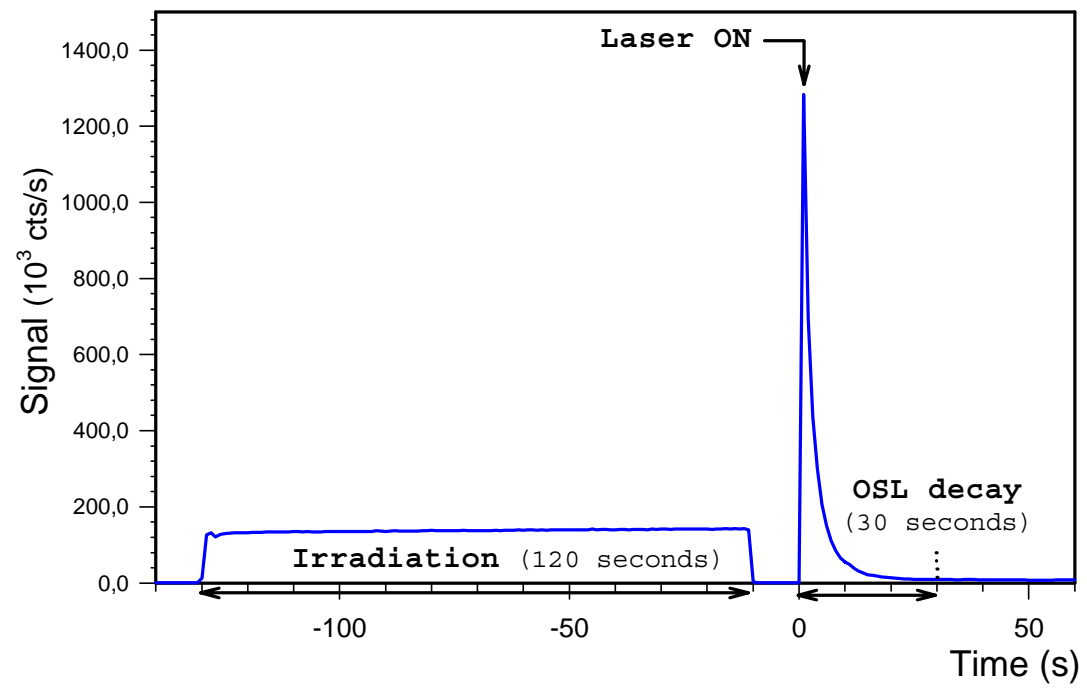

Fig. 2.: Typical RL/OSL signals obtained with the fibre sensors depicted on fig. 1 ( $\dot{D}=0.15 \mathrm{~Gy} / \mathrm{min}$, Dose $=0.3 \mathrm{~Gy})$

\section{ACKNOWLEDGEMENTS}

This work is done in the framework of the European project IP CE503564 MAESTRO (Methods and Advanced Equipments for the Simulation and Treatment in Radio Oncology) granted by the European Commission.

\section{REFERENCES}

1. M.C. Aznar, C.E. Andersen, L. Boetter-Jensen, S. A.J. Bäck, S. Mattson, F. Kjær-Kristoffersen and J. Medin, "Realtime optical-fibre Luminescence Dosimetry for Radiotherapy : Physical Characteristics and Applications in Photon Beams", Phys. Med. Biol. 49, 1655-1669 (2004).

2. R. Gaza, S.W.S. Mc Keever, M.S. Akselrod, A. Akselrod, T. Underwood, C. Yoder, C.E. Andersen, M.C. Aznar, C.J. Marckmann, L. Boetter-Jensen, "A Fiber-Dosimetry Method Based on OSL from $\mathrm{Al}_{2} \mathrm{O}_{3}$ :C for Radiotherapy Applications", Rad. Meas. 38, 809-812 (2004).

3. B.L. Justus, P. Falkenstein, A. L. Huston, M. C. Plazas, H. Ning and R. W. Miller, "Gated Fiber-Optic-Coupled Detector for In-vivo Real-Time Radiation Dosimetry”, Appl. Opt. 43(8), 1663-1668 (2004).

4. M. S. Akselrod, V. S. Kortov, and E. A. Gorelova, "Preparation and properties of $\alpha-\mathrm{Al}_{2} \mathrm{O}_{3}: \mathrm{C}^{\prime}$, Rad. Prot. Dos. 47(1/4), 159-164 (1993).

5. S. Magne and P. Ferdinand, "Fiber Optic remote $\gamma$ Dosimeters based on Optically Stimulated Luminescence: Stateof-the Art at CEA", IRPA 11, Madrid (2004).

6. G. Ranchoux, S. Magne, J.P. Bouvet and P. Ferdinand, "Fiber Remote Optoelectronic Gamma Dosimetry based on Optically Stimulated Luminescence of $\mathrm{Al}_{2} \mathrm{O}_{3}:$ C", Rad. Prot. Dos. 100(1-4), 255-260 (2002).

7. C.E. Andersen, C.J. Marckmann, M.C. Aznar, L. Boetter-Jensen, F. Kjaer-Krisstoferson and J. Medin, “An Algorithm for Real-time Dosimetry in Intensity-Modulated Radiation Therapy using the RadioLuminescence Signal from $\mathrm{Al}_{2} \mathrm{O}_{3}$ :C", Rad. Prot. Dos. 120(1-4), 7-13 (2006). 